\title{
Optimization of Electrocoagulation on Removal of Wastewater Pollutants
}

Mazen Hamada ${ }^{1 *}$, Nasser Abu Ghalwa ${ }^{1}$, Nader B. Farhat ${ }^{1}$, Khamis AI Mahllawi ${ }^{2}$ and Najma Jamee ${ }^{3}$

${ }^{1}$ Chemistry Department, Al Azhar University, Gaza, Palestine

${ }^{2}$ Environment Quality Authorities, Gaza, Palestine

3Institue of Water and Environmental Sciences, Al Azhar University, Gaza, Palestine

"Corresponding author: Mazen Hamada, Chemistry Department, Al Azhar University, Gaza, Palestine, Tel: 00970599461322; E-mail: dr.mazenhamada@gmail.com

Received date: August 31, 2018; Accepted date: September 20, 2018; Published date: September 27, 2018

Copyright: ( 2018 Hamada M, et al. This is an open access article distributed under the terms of the Creative Commons Attribution License, which permits unrestricted use, distribution and reproduction in any medium, provided the original author and source are credited.

\begin{abstract}
In this work the performance of electrocoagulation (EC) process was investigated and optimized under different operational conditions for the best removal of wastewater contaminants such as Nitrate, total hardness, Calcium and Magnesium. Samples were obtained from Gaza Wastewater Treatment Plant (GWWTP). Under the optimal condition ( $\mathrm{pH}=7.45$, inter-electrode spacing $=1 \mathrm{~cm}$, operating time $=40$ minutes and current density $=3.18 \mathrm{~mA} / \mathrm{cm}^{2}$ ), the results showed that the removal efficiency of total hardness, Calcium, Magnesium, Nitrate were $94.6 \%, 93.3 \%$, $95.2 \%$ and $70.9 \%$ respectively by using stainless steel electrodes, while for aluminum electrodes the results were $92.83 \%, 93.33 \%, 92.30 \%, 50.43 \%$ respectively. For Iron electrodes, the removal efficiencies of contaminants were $87.84 \%, 88 \%, 87.64 \%, 57.26 \%$ respectively. In addition, the experimental results also showed that the effluent wastewater was very clear, odorless and its quality is fit for reuse.
\end{abstract}

Keywords Electrocoagulation; Removal efficiency; Wastewater treatment; Electrodes types; Total hardness; Calcium; Magnesium; Nitrate

\section{Introduction}

The reuse of wastewater has become an absolute necessity. Demands to the cleaning industrial and domestic wastewater to avoid environmental pollution and especially contamination of pure water resources are becoming national and international issues. The Gaza Strip is described as one of the most exploited places in the world where the level of demand on water and land resources exceed the capacity of the environment due to water shortage, contamination of water resources, densely populated area and highly intensive irrigated agriculture characterize. The water balance records revealed a water deficit of $80 \times 106 \mathrm{~m}^{3}$ in 2012 [1]. The use of wastewater as a supplemental source of irrigation is inevitable for increased agricultural production in the Gaza Strip, where irrigation supplies are insufficient to meet crop water needs. Moreover, irrigation with treated wastewater is considered a promising practice that helps in minimizing the pollution of the ecosystem subjected to contamination by direct disposal of wastewater into surface or groundwater. The treated wastewater has several advantages over other sources of water, it minimizes pollution, augments groundwater resources by artificial recharge and it is a good nutrient source for landscape and farm irrigation [2]. Different technologies have been reported for the treatment of water and wastewater such as: nanotechnology [3-7], Photocatalytic [8], Advanced Oxidation Processes [9] and Solar Energy [10]. In the last years, there is an increasing interest in the development of environmentally friendly electrochemical methods to treat of water. Electrocoagulation (EC) is one of the novel methods for wastewater treatment. The EC process possesses several advantages such as easy operation, short treatment time, low sludge production and no chemical requirement $[11,12]$. A literature survey indicates that EC is an efficient treatment process for different wastes, e.g. soluble oils, liquid from the food, textile industries and effluents from the paper industry, aquacultural wastewater, textile wastewater, herbicide and polymer [13-21].

In this study, electrocoagulation has been suggested as an advanced alternative in pollutant removal from wastewaters to improve the effluent quality prior to wastewater reuse for agriculture purposes. This research is mainly focused on the capability of EC technology to improve wastewater quality by removal of Nitrate, Total hardness, Calcium, Magnesium and other pollutants from the Gaza wastewater treatment plant under different operational conditions.

\section{Experiment}

\section{Chemicals}

Sodium chloride, sodium sulfate, sodium carbonate, potassium nitrate, sodium hydroxide, sulfuric acid and potassium dichromate, were of analytical grade and purchased for the preparation of standard solution from Merck. Standard solutions of potassium dichromate $\left(\mathrm{K}_{2} \mathrm{Cr}_{2} \mathrm{O}_{7}\right)$, sulfuric acid $\left(\mathrm{H}_{2} \mathrm{SO}_{4}\right)$ reagent with silver sulfate $\left(\mathrm{Ag}_{2} \mathrm{SO}_{4}\right)$ and Mercury sulfate $\left(\mathrm{HgSO}_{4}\right)$ were prepared to measure the COD.

\section{Equipment and procedure}

For electrochemical tests in this work, different electrodes types were used such as stainless steel (Ss), iron $(\mathrm{Fe})$ plate and aluminium (Al) electrodes. The total effective electrode area and the distance between electrodes, electrode type, electrode size, $\mathrm{pH}$, current intensity and time were used as variable factors may affect the pollutants removal efficiencies. Before each run, electrodes were washed with Potassium Chloride solution to remove surface grease. At the end of each run, the electrodes were washed thoroughly with water to remove any solid residues on the surfaces and dried. The experiments were conducted in a $1000 \mathrm{ml}$ glass beaker in batch mode of operation. The volume of wastewater sample was $600 \mathrm{ml}$. Aluminum; iron and 
stainless-steel sheets with dimensions of $270 \mathrm{~mm} \times 40 \mathrm{~mm} \times 1.8 \mathrm{~mm}$ (length $\times$ width $\times$ thickness) were used as electrodes. The area of electrodes dipped into the solution was $50.88 \mathrm{~cm}^{2}$. Power supply was started at time zero $(t=0)$ and it was the starting time of the EC process. After $30 \mathrm{~min}, 40 \mathrm{~min}, 1$ hour, the samples were withdrawn, filtered using filter paper $(0.45 \mu \mathrm{m})$, and analyzed. The schematic diagram of the experimental set up is shown in Figure 1.

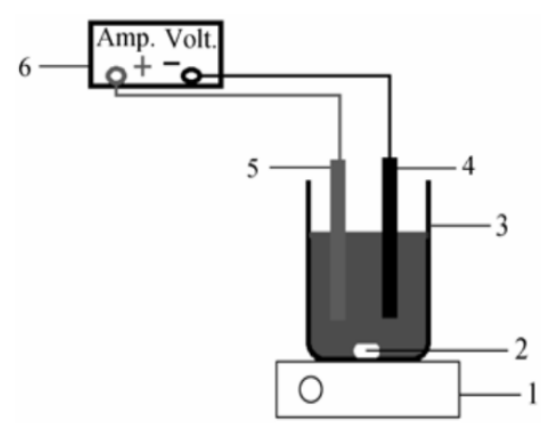

Figure 1: Experimental setup: where 1-magnetic stirrer; 2-magnetic bar; 3-beaker; 4-cathode; 5-anode; 6-DC power supply.

\section{Analysis}

The equation used to calculate the wastewater removal efficiency and COD in the treatment experiments was [22,23]:

$$
C R=\frac{C_{0}-C_{1}}{C_{0} \times 100 \%}
$$

Where,

$\mathrm{CR}$ is the removal efficiency percentage; $\mathrm{C}_{0}$ is initial concentration of wastewater before electrocoagulation in $\mathrm{m} \mathrm{L} \mathrm{L}^{-1}$.

\section{Results and Discussion}

In an EC experiment the electrode or electrode assembly is usually connected to an external DC source. The amount of metal dissolved or deposited is dependent on the quantity of electricity passed through the electrolytic solution [24]. If in this process $M$ is considered as anode, the following reactions will occur [25]:

At anode:

$M(s) \rightarrow M \quad n+(a q)+n e^{-}$

$2 \mathrm{H}_{2} \mathrm{O} \rightarrow 4 \mathrm{H}+(g)+\mathrm{O}_{2}(g)+4 e^{-}$

At cathode:

$$
M n+(a q)+n \quad e^{-} \rightarrow M(s)
$$

$2 \mathrm{H}_{2} \mathrm{O}+2 e^{-} \rightarrow \mathrm{H}_{2}(g)+2 \mathrm{OH}^{-}(5)$

Where $\mathrm{M}$ is the material used as electrode and $\mathrm{n}$ is the number of electrons.

\section{Effect of electrodes materials}

Electrode assembly is the heart of the present treatment facility. The most common electrode materials for electrocoagulation are iron, aluminum and stainless steel [26]. The experimental removal efficiencies for Total hardness, Calcium, Magnesium, and Nitrate were $(92.83 \%, 93.33 \%, 92.30 \%$ and $50.43 \%)$ respectively for aluminum electrode as shown in Figure 2 and for stainless steel electrode removal efficiencies of the above mentioned water quality parameters (Total hardness, Calcium, Magnesium and Nitrate) were 94.26\%, 93.33\%, $95.19 \%$ and $70.94 \%$, respectively and for iron electrode were $87.84 \%$, $88 \%, 87.64 \%$ and $57.26 \%$, respectively. The effluent treated with iron electrode, appeared firstly greenish color and then turned yellow color and turbid in the first minutes. This green and yellow color may be resulted from $\mathrm{Fe}^{2+}$ and $\mathrm{Fe}^{3+}$ ions generated during EC process. $\mathrm{Fe}^{2+}$ is the common ion generated in situ of electrolysis of iron electrode. It has relatively high soluble at acidic or neutral conditions and can be oxidized easily into $\mathrm{Fe}^{3+}$ by dissolved oxygen in water [27], where the effluent treated with aluminum electrode appeared as the first time white and stay white all the process, no sludge settled remarked, only white foam is formed as the electrode was eroded and liberated trivalent aluminum $\left(\mathrm{Al}^{3+}\right)$. The $\left(\mathrm{Al}^{3+}\right)$ formed an ionic pair with the pollutant of wastewater rich in magnesium and Calcium. There was formation of a strong coagulant. An excellent flocculation and coagulation was observed. The Stainless steel electrodes used to treat the effluent release in the first of process black color and after a few minutes it starts to appear clear and a little of sludge is formed. In general the electrocoagulation process increases due to the formation of metal hydroxide species which adsorbed the pollutants molecules, and this causes the increase of the removal efficiency (Figure 3) [28-29].

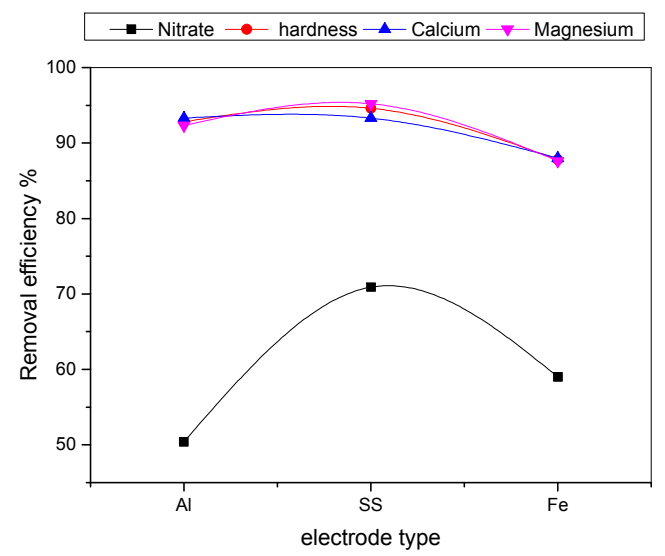

Figure 2: Effect of electrodes types on pollutants removal.

\section{Effect of current density (mA.cm $\left.{ }^{-2}\right)$}

The applied current controls the anode dissolution speed on one hand and the formation of hydrogen on the other hand [30]. The influence of the variation of this parameter between (1.18-3.18 $\mathrm{mA} . \mathrm{cm}^{2}$ ) has been examined on the removal efficiency for the total hardness, Calcium, Magnesium, and Nitrate at 40 minutes, electrode distance of $1 \mathrm{~cm}$ and $\mathrm{pH} 7.45$. Figures 3 and 4 indicate that a current of $3.18 \mathrm{~mA} / \mathrm{cm}^{2}$ give the maximum rates of pollutants removal for total hardness, calcium, magnesium and nitrate using stainless steel and 
Citation: Hamada M, Ghalwa NA, Farhat NB, Mahllawi K, Jamee N (2018) Optimization of Electrocoagulation on Removal of Wastewater

aluminum electrode. The increase of current density increases the number of metal cation dissolution from anode, formation of $\mathrm{H}_{2}$ bubbles (Figures 3 and 4). However, the higher the current density the smaller the size of the hydrogen bubbles which lead to a faster removal of pollutant [30,31].

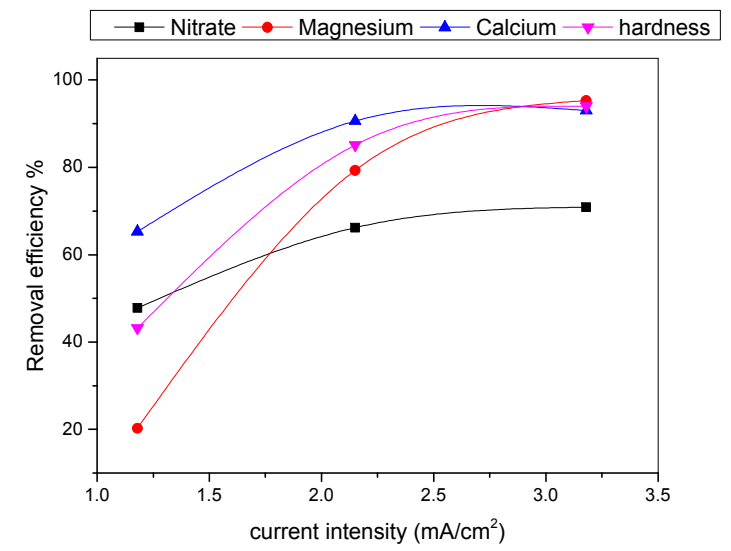

Figure 3: Effect of current density on pollutants removal using SS electrodes.

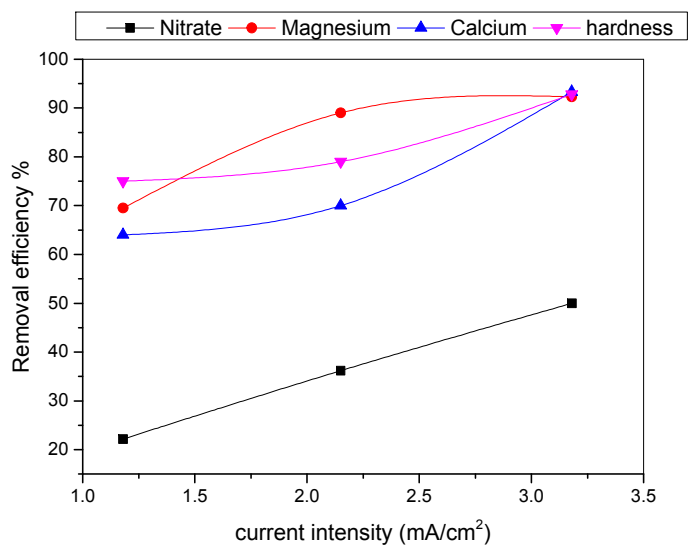

Figure 4: Effect of current density on pollutants removal using $\mathrm{Al}$ electrodes.

\section{Effect of initial pH}

The process of electrocoagulation is proved to be highly $\mathrm{pH}$ dependent. Experiments were performed by applying an initial $\mathrm{pH}$ in the range of (5-11.8) at 40 minutes, electrode distance of $1 \mathrm{~cm}$ and current density $3.18 \mathrm{~mA} / \mathrm{cm}^{2}$. As shown Figures 5-7, total hardness, calcium and magnesium removal efficiencies were found to be the best near basic $\mathrm{pH}$ using the three types of electrodes as they were above $95 \%$, but the highest one was by using aluminum electrode as it achieves $97.43 \%, 94.67$, and $100 \%$ respectively. As the operating time of EC process increased the $\mathrm{pH}$ value increased. This is due to the $\mathrm{OH}^{-}$ ion accumulation in aqueous solution during the process. From figure $5-7$, it can be seen that the removal efficiency of waste water was increased by increasing the $\mathrm{pH}$.

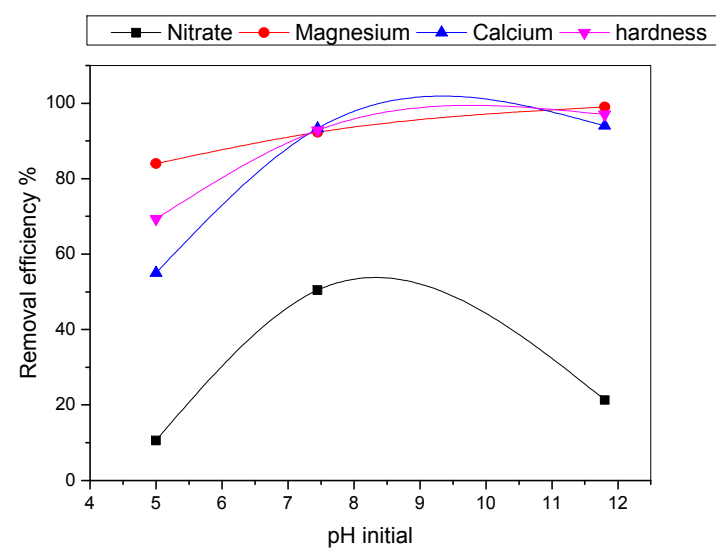

Figure 5: Effect of $\mathrm{pH}$ on pollutants removal using $\mathrm{Al}$ electrodes.

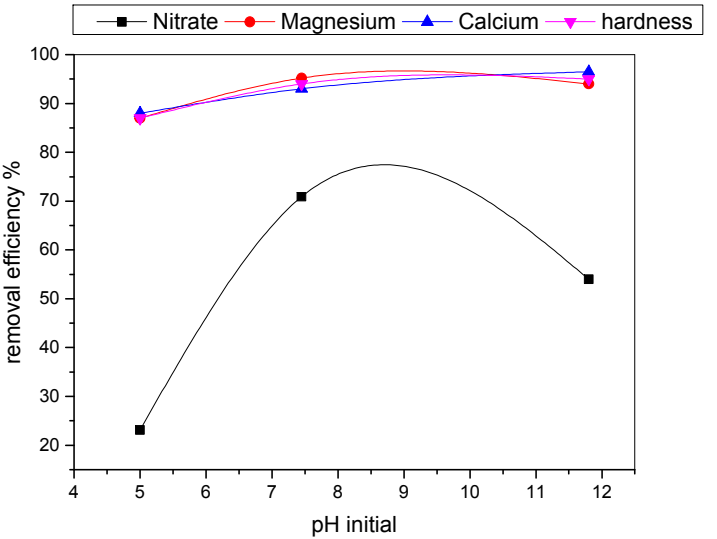

Figure 6: Effect of $\mathrm{pH}$ on pollutants removal using SS electrodes.

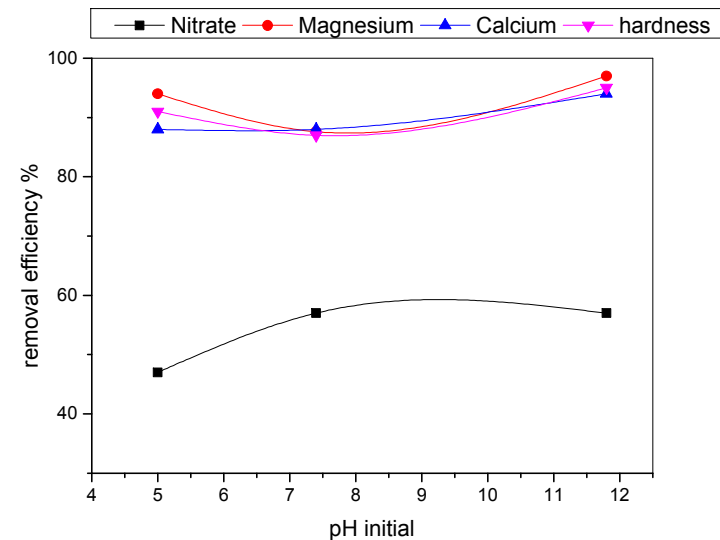

Figure 7: Effect of $\mathrm{pH}$ on pollutants removal using Fe electrodes. 


\section{Effect of operating time}

The EC time is a significant parameter which has a vital importance and influence on the performance of EC process. In this experiment the effect of time was studied at constant current density of 3.18 $\mathrm{mA} / \mathrm{cm}^{2}$ and constant distance $1 \mathrm{~cm}$. Table 1 illustrates the effect of retention time on the removal of chemical and physical pollutants using three different electrodes $\mathrm{Al}, \mathrm{Ss}$ and $\mathrm{Fe}$ ) at neutral $\mathrm{pH}$. In this process, EC involves two stages which are destabilization and aggregation. The first stage is usually short, whereas the second stage is relatively long. Results show that the efficiency start to be significant for some pollutant at the treatment time of 30 minutes but the maximum efficiency was obtained at a treatment time of 40 minutes. Treatment time has significant improvement in the removal efficiency for the studied pollutants. It is assumed that the more time consumed, especially above 30 minutes, the more production rate of hydroxyl and metal ions on the electrodes.

\begin{tabular}{|c|c|c|c|c|c|c|c|}
\hline \multirow{2}{*}{$\begin{array}{l}\text { Time } \\
(\min )\end{array}$} & \multirow{2}{*}{$\begin{array}{c}\text { Electrode } \\
\text { types }\end{array}$} & \multicolumn{6}{|c|}{ Pollutants Removal\% } \\
\hline & & $\begin{array}{l}\text { Hardne } \\
\text { ss }\end{array}$ & $\underset{\mathrm{m}}{\text { Calciu }}$ & $\underset{\mathrm{m}}{\operatorname{Magnesiu}}$ & $\begin{array}{c}\text { Turbidi } \\
\text { ty }\end{array}$ & $\begin{array}{c}\text { Nitrat } \\
\text { e }\end{array}$ & TDS \\
\hline \multirow{3}{*}{20} & Al & 79.05 & 70 & 88.33 & 72.21 & 27.35 & $\begin{array}{c}20.4 \\
5\end{array}$ \\
\hline & Ss & 82.43 & 78.66 & 86.26 & 47.02 & 22.22 & $\begin{array}{c}17.0 \\
5\end{array}$ \\
\hline & $\mathrm{Fe}$ & 80.4 & 73.33 & 77.88 & 71 & 23.08 & $\begin{array}{c}11.3 \\
6\end{array}$ \\
\hline \multirow{3}{*}{30} & Al & 92.57 & 92 & 93.13 & 76.13 & 35.9 & $\begin{array}{c}22.7 \\
3\end{array}$ \\
\hline & Ss & 89.86 & 92 & 87.64 & 81.57 & 26.5 & $\begin{array}{c}20.4 \\
5\end{array}$ \\
\hline & $\mathrm{Fe}$ & 81.76 & 85.33 & 78.02 & 74.62 & 31.62 & $\begin{array}{c}14.7 \\
7\end{array}$ \\
\hline \multirow{3}{*}{40} & Al & 92.83 & 93.33 & 92.3 & 95.2 & 50.43 & $\begin{array}{c}22.9 \\
5\end{array}$ \\
\hline & Ss & 94.26 & 93.33 & 95.19 & 94.56 & 70.94 & $\begin{array}{c}29.0 \\
9\end{array}$ \\
\hline & $\mathrm{Fe}$ & 87.84 & 88 & 87.64 & 93.35 & 57.26 & $\begin{array}{c}22.0 \\
5\end{array}$ \\
\hline
\end{tabular}

Table 1: Influence of time on pollutants removal using three types of electrodes

\section{Effect of distance between electrodes}

To investigate the influence of electrode distance on the elctrocoagulation process for the removal of pollutants from effluent, different spaces between the electrodes were applied. According to Bukhari [32], increasing the electrodes spacing will reduce the capital cost of treatment but may reduce the treatment efficiency. Interelectrode spacing of 1,2 and $3 \mathrm{~cm}$ was studied to examine the effect of electrode distance on the EC process for Stainless steel and Aluminum electrodes. Table 2 summarizes the influence of distance between electrodes on the removal of physical and chemical pollutants using three types of electrodes, AL, Fe and SS. The analysis reveals that the removal efficiency for EC process for total hardness, calcium, magnesium, turbidity, nitrate, TDS increased with the decrease in the interel electrode spacing. For total hardness, calcium and magnesium, an inter-spacing electrode of $1 \mathrm{~cm}$ marked a significant percent of removal at 40 minutes for all type of electrodes.

In addition the odor was disappear by using stainless electrodes, and slightly smelt with iron and Aluminum electrodes, and the color of the sample had changed to colorless for all type of electrodes. Where removal of COD during the experiment in the range of $74 \%$ for stainless steel, $68.18 \%$ for aluminum and $67.27 \%$ for iron in an interval of 30-40 minutes at neutral medium. The COD removal by aluminum and iron electrodes was thought to be mainly adsorption of pollutants onto aluminum and iron hydroxide sludge.

\begin{tabular}{|c|c|c|c|c|c|c|c|}
\hline \multirow{2}{*}{$\begin{array}{l}\text { Distance } \\
\text { between } \\
\text { electrod } \\
\text { es }(\mathrm{cm})\end{array}$} & \multirow{2}{*}{$\begin{array}{c}\text { Electro } \\
\text { de } \\
\text { types }\end{array}$} & \multicolumn{6}{|c|}{ Pollutants Removal \% } \\
\hline & & $\begin{array}{l}\text { Hardne } \\
\text { ss }\end{array}$ & $\underset{\mathrm{m}}{\text { Calciu }}$ & $\underset{\mathrm{m}}{\text { Magnesiu }}$ & $\begin{array}{c}\text { Turbidit } \\
y\end{array}$ & $\begin{array}{c}\text { Nitrat } \\
\text { e }\end{array}$ & $\begin{array}{c}\text { TD } \\
S\end{array}$ \\
\hline \multirow{3}{*}{1} & Al & 92.83 & 93.33 & 92.3 & 95.2 & 50.43 & 23 \\
\hline & Ss & 94.26 & 93.33 & 95.19 & 94.56 & 70.94 & $\begin{array}{c}29 . \\
1\end{array}$ \\
\hline & $\mathrm{Fe}$ & 87.84 & 88 & 87.64 & 93.35 & 59.26 & $\begin{array}{c}22 . \\
1\end{array}$ \\
\hline \multirow{2}{*}{2} & $\mathrm{Al}$ & 82.43 & 80 & 84.89 & 93.6 & 29.91 & $\begin{array}{c}18 . \\
6\end{array}$ \\
\hline & Ss & 89.86 & 90.67 & 89.01 & 93.6 & 62.82 & $\begin{array}{c}29 . \\
6\end{array}$ \\
\hline \multirow{2}{*}{3} & $\mathrm{Al}$ & 72.97 & 53.33 & 93.13 & 92.54 & 24.36 & $\begin{array}{c}20 . \\
7\end{array}$ \\
\hline & Ss & 88.51 & 89.33 & 87.64 & 89 & 48.29 & 20 \\
\hline
\end{tabular}

Table 2: Influence of inter electrode distance on pollutants removal using different type of electrodes.

\section{Treated Wastewater Reuse}

In this research the technology of EC is investigated to achieve the quality standard for wastewater irrigation. Recently the Environment Quality Authority with coordination of Palestinian ministries and universities has established specific wastewater reuse regulations. Table 3 presents the characteristics of the wastewater used in the experiments before EC where Table 4 presents the values of chemical, physical and biological contaminants after EC treatment and the Palestinian standards for wastewater reuse. According to the results of the EC experiments, the quality of treated wastewater in general is within the acceptable limits for all investigated parameters. 


\begin{tabular}{|c|c|c|}
\hline Parameters & Unit & Value \\
\hline $\mathrm{pH}$ & - & 7.45 \\
\hline COD & $\mathrm{mg} \mathrm{O2/l}$ & 550 \\
\hline Color & - & dark brown \\
\hline Turbidity & $\mathrm{NTU}$ & 33.1 \\
\hline Conductivity & $\mu \mathrm{S} / \mathrm{cm}$ & 4400 \\
\hline TDS & $\mathrm{mg} / \mathrm{l}$ & 2728 \\
\hline Hardness & $\mathrm{mg} / \mathrm{l}$ & 740 \\
\hline Calcium & $\mathrm{mg} / \mathrm{l}$ & 150.4 \\
\hline Magnesium & $\mathrm{mg} / \mathrm{l}$ & 88.34 \\
\hline Sodium & $\mathrm{mg} / \mathrm{l}$ & $575-600$ \\
\hline SAR & - & 9.18 \\
\hline Nitrate & $\mathrm{mg} / \mathrm{l}$ & 23.4 \\
\hline Odor & - & very bad \\
\hline Fecal coliform & colonies/100 milli liters & $2 * 105$ \\
\hline Chloride & $\mathrm{mg} / \mathrm{l}$ & 920 \\
\hline
\end{tabular}

The different electrode materials had an effect on the effectiveness of wastewater treatment because of its mechanisms. Aluminum electrodes marked the highest removal in turbidity (95.20\%). Stainless steel electrodes marked highest removal of total hardness $(94.26 \%)$, calcium (93.33\%), and magnesium (95.19\%), TDS (29.09\%), nitrate (70.94\%) and turbidity (94.56\%). Iron electrodes have good removal efficiency and can also be applied for wastewater treatment as it is the cheapest one.

The applied current density has important effect on the removal efficiency of EC process. It was found that rising the current density from 1.15 to $3.18 \mathrm{~mA} / \mathrm{cm}^{2}$ increases the removal efficiency for studied pollutants.

Removal of COD during the experiment in the range of $74 \%$ for stainless steel, $68.18 \%$ for aluminum and $67.27 \%$ for iron electrode

The results obtained after EC meet the Palestinian standards for wastewater reuse.

\section{References}

1. Palestinian Water Authority (PWA) (2012) Agricultural and Municipal Water Demand in Gaza Governorates for 2010, Strategic Planning Directorate.

2. Saleem M, Bukhari AA, Al-Malack MH (2000) Removal efficiencies of indicator micro-organisms in the Al-Khobar wastewater treatment plant. Environ Eng Sci 17: 227-232.

Table 3: Characteristics of the wastewater used in the experiments

\begin{tabular}{|c|c|c|c|c|}
\hline \multirow{2}{*}{ Pollutants } & \multicolumn{3}{|c|}{ Type of electrodes } & Palestinian \\
\hline & Al & Ss & $\mathrm{Fe}$ & \\
\hline Calcium (mg/l) & 10 & 10 & 18 & 400 \\
\hline Magnesium (mg/l) & 6.79 & 4.25 & 19.92 & 60 \\
\hline SAR & 7.01 & 7.68 & 7.52 & $9-10$ \\
\hline Nitrate $(\mathrm{mg} / \mathrm{l})$ & 11.6 & 6.8 & 10 & $15-50$ \\
\hline Turbidity (NTU) & 1.95 & 1.8 & 2.2 & NA \\
\hline $\mathrm{EC}(\mu \mathrm{S} / \mathrm{cm})$ & 3390 & 3120 & 3430 & $2400-3000$ \\
\hline TDS (mg/l) & 2102 & 1934 & 2127 & $1200-1500$ \\
\hline $\mathrm{pH}$ & 9 & 8.2 & 8.1 & $6-9$ \\
\hline COD (mg/l) & 175 & 139 & 180 & $150-200$ \\
\hline Fecal coliform (colonies/100 ml) & 0 & 0 & 1 & $200-1000$ \\
\hline Colour & free & free & free & Free \\
\hline
\end{tabular}

Table 4: Comparison of chemical, physical and biological values of the Palestinian standards with effluent after EC treatment.

\section{Conclusion}

The optimized conditions for this process were as follows: a current density of $3.18 \mathrm{~mA} / \mathrm{cm}^{2}$, inter-electrode spacing of $1 \mathrm{~cm}$, retention time of 40 minutes and neutral $\mathrm{pH}$ (7.45).

3. Alswat AA, Bin Ahmad M, Hussein MZ, Ibrahim NA, Saleh TA (2017) Copper oxide nanoparticles-loaded zeolite and its characteristics and antibacterial activities. Journal Materials Science and Technology 33: 889-896.

4. Alswat AA, Ahmad MB, Saleh TA (2017) Preparation and Characterization of ZeolitelZinc Oxide-Copper Oxide Nanocomposite: Antibacterial Activities. Colloid and Interface Science Communications 16: 19-24.

5. Alswat AA, Ahmad MB, Saleh TA, Hussein MZB, Ibrahim N (2017) Effect of zinc oxide amounts on the properties and antibacterial activities of zeolite/zinc oxide nanocomposite. Mater Sci Eng C Mater Biol Appl 68: 505-511.

6. Bello OA, Tawabini BS, Khalil AB, Boland CR, Saleh TA (2018) Phytoremediation of cadmium, lead and nickel contaminated water by Phragmites australis in hydroponic systems. Ecological Engineering 120: 126-133.

7. Saleh TA, Gupta VK (2016) Nanomaterial and Polymer Membranes 1st Edition Synthesis, Characterization, and Applications 207-284.

8. Lazar MA, Varghese S, Nair SS (2012) Photocatalytic Water Treatment by Titanium Dioxide. Catalysts 2: 572-601.

9. Deng Y, Zhao R (2015) Advanced Oxidation Processes (AOPs) in Wastewater Treatment. Curr Pollution Rep 1: 167-176.

10. Kale DN, Desai AA, Khan AH, Pawar CD, Chougule VN (2017) Development of waste water treatment using solar energy. Journal of Mechanical and Civil Engineering 49-54.

11. Gengec E, Kobya M, Demirbas E, Akyol A, Oktor K (2012) Optimization of baker's yeast wastewater using response surface methodology by electrocoagulation. Desalination 286: 200-209.

12. Chafi M, Gourich B, Essadki AH, Vial C, Fabregat A (2011) Comparison of electrocoagulation using iron and aluminium electrodes with chemical coagulation for the removal of a highly soluble acid dye. Desalination 281: 285-292.

13. Carmona M, Khemis M, Leclerc JP, Lapicque F (2006) A simple model to predict the removal of oil suspensions from water using the electrocoagulation technique. Chem Eng Sci 61: 1237-1246. 
Citation: Hamada M, Ghalwa NA, Farhat NB, Mahllawi K, Jamee N (2018) Optimization of Electrocoagulation on Removal of Wastewater Pollutants. Int J Waste Resour 8: 357. doi:10.4172/2252-5211.1000357

Page 6 of 6

14. Holt PK, Barton GW, Wark M, Mitchell CA (2002) A quantitative comparison between chemical dosing and electrocoagulation. Colloids Surfaces A: Physicochem Eng Asp 211: 233-248.

15. Calvo LS, Leclerc JP, Tnguy G, Cames MC, Paternotte G, et al. (2003) An electrocoagulation unit for the purifcation of soluble oil wastes of high COD. Environ Prog 22: 57-65.

16. Larue O, Vorobiev E (2003) Floc size estimation in iron induced electrocoagulation and coagulation using sedimentation data. Int J Mineral Proc 71: 1-15.

17. Lin SH, Wu CL (1996) Electrochemical removal of nitrite and ammonia for aquaculture. Water Res 30: 715-721.

18. Lin SH, Peng CF (1996) Continuous treatment of textile wastewater by combined coagulation. Water Res 30: 587-592.

19. Lin SH, Chen ML (1997) Treatment of textile wastewater by chemical methods for reuse. Water Res 31: 868-876.

20. Ghalwa N, Musabeh AZ, Farahat NB (2016) Optimization of electrocoagulation (EC) process for the purification of water from 2,4dichlorophenoxyacetic acid (2,4-D) using sacrificial anodes. International Journal of Innovative Research in Science, Engineering and Technology 5: 2760-2778.

21. Ghalwa NM, Romia RS, Farhat NB, Alasqalan MY (2016) Electrocoagulation (EC) of styrene butadiene rubber from aqueous solution using different electrodes. International Journal of Nanotechnology in Medicine and Engineering 1: 37-49.

22. Mollah MY, Schennach R, Parga JR, Cocke DL (2001) Electrocoagulation (EC) science and applications. J Hazard Mater 84: 29-41.
23. Carneiro PA, Fugivara CS, Nogueira FP, Boralle N, Zanoni VB (2003) A Comparative on Chemical and Electrochemical Degradation of Reactive Blue 4 Dye. Portugaliae Electrochimica Acta 21: 49-67.

24. Paul AB (1996) Proceedings of the 22nd WEDC Conference on Water Quality and Supply, New Delhi, India 286.

25. Moreno CHA, Cocke DL, Gomes JAG, Morkovsky P, Parga JR, et al. (2009) Electrochemical reactions for electrocoagulation using iron electrodes. Ind Eng Chem Res 48: 2275-2282.

26. Chen G (2004) Electrochemical Technologies in Wastewater Treatment. Separation and Purification Technology 38:11-41.

27. Ramesh R, Babu NS, Bhadrinarayana K (2007) Treatment of Tannery wastewater by electrocoagulation. Journal of the University of Chemical Technology and Metallurgy 42: 201-206.

28. Ghosh D, Medhi CR, Solanki H, Purkait MK (2008) Decolorization of Crystal Violet Solution by Electrocoagulation. J environ Protect 2: 25-35.

29. Entezari MH, Heshmati A, Sarafraz-Yazdi A (2005) A combination of ultrasound and inorganic catalyst: Removal of 2-chlorophenol from aqueous solution. Ultrason Sonochem 12: 137-141.

30. Chen X, Chen G, Yue PL (2000) Separation of pollutants from restaurant wastewater by electrocoagulation. Sep Purif Technol 19: 65-76.

31. Mollah MY, Morkovsky P, Gomes JA, Kesmez M, Parga J, et al. (2004) Fundamentals, present and future perspectives of electrocoagulation. J Hazard Mater 114: 199-210.

32. Bukhari A (2008) Investigation of the electro-coagulation treatment process for the removal of total suspended solids and turbidity from municipal wastewater. Bioresource Technology 99: 914-921. 